\title{
Research on the Relationship between Quality Education and College English Teaching Reform
}

\author{
Ma Yufei \\ Foreign Language Research Center, Shaanxi Academy of Governance, Shaanxi, China, 710068
}

Keywords: Quality Education; English Teaching; Reform

Abstract: After years of rapid development, Chinese higher education has achieved remarkable achievements in many aspects. However, while we affirm our achievements, we must also clearly see the problems and deficiencies in our own development and reform. Especially in today's advocacy of quality education, many of our thoughts and practices can not fully adapt to the development of the times and the continued rapid advancement of higher education, and even some of drawbacks have become a drag in development and reform. How to deal with the relationship between quality education and college English teaching reform and let the two complement each other is an urgent problem to be solved in front of every educator.

\section{Introduction}

As an international communicative language, English plays an indispensable role in people's communication. As a branch of the quality education system, the college English course also shoulders the heavy responsibility of leading the society and culture, and the mission of cultivating qualified talents for the country's modernization. It plays an irreplaceable role in cultural inheritance, humanistic cultivation, and personality shaping. From a certain perspective, quality education and college English teaching are closely integrated and inseparable from the beginning. However, there is still a big gap between college English teaching and the general requirements of quality education due to historical reasons.

\section{The Relationship between Quality Education and College English Teaching}

What is quality education, and quality education requires students to have what kind of English quality, which is a complex issue. Quality is a macro concept, which refers to the collective name of human survival and development ability and endowment. The way to improve people's quality is generally achieved through education. Quality education refers to the use of culture and education to promote people's natural ability and social ability development. Comprehensive and harmonious promotion of the overall quality of students, that is, the basic qualities of nature, psychology, social culture and other aspects. The quality of ideological cultivation is the basic component of quality education. Quality education is a relatively open and democratic concept of education guided by individual subjective wishes. This kind of education runs through the whole process of talent cultivation. The fundamental purpose of quality education is to let students learn to learn by 
themselves and learn to do things and behave through education. English quality is actually only a small aspect of quality education, and its purpose is to enable students to master the skills of English learning and the basic knowledge of English, and to some extent stimulate students' learning potential. The quality of people will not be revealed naturally, and only through the exploration of educational activities can they be externalized and displayed. However, ability is not the same as quality, and internalization of ability can be precipitated as quality. At present, there are many problems in the teaching of English in colleges and universities, which has aroused widespread concern in society. Many educators have made unremitting research and exploration on how to reform the current college English teaching under the general requirements of quality education. Both in theory and in practice, they have achieved fruitful results. The core of our college English teaching reform is to train students in all aspects of quality, not only in the classroom, but also to expand the shaping of students' ability literacy to extracurricular. We must pay attention to the all-round development of students, strengthen the cultivation of students' morality and taste in education and teaching, enhance students' thinking, innovation and cooperation ability, etc., and help students to establish correct attitude towards foreign culture and awareness of cross-cultural communication.

\section{The Status Quo of College English Education under the Background of Quality Education}

Our culture has always been very inclusive and diverse. College English teaching is an important component of this diversity. Since its establishment, college English teaching has been devoted to improving students' skills in all aspects of English learning. However, due to historical reasons such as school experience and financial constraints, Chinese English teaching has taken some detours in its development. After the reform and opening up, English teaching in colleges and universities ushered in the golden stage of development, and achieved very remarkable results, but the drawbacks still exist. The existence of these problems is not conducive to stimulating and enhancing the potential of students in education and teaching, which is not conducive to the improvement of teaching quality. As far as the author believes, the main problems in the current English teaching in colleges and universities in China are shown as following.

\subsection{Lack of Flexible Use of English Textbooks}

Similar to the problem of most teaching modes, English teaching is often difficult to get rid of the constraints of textbooks. These textbooks are usually compiled by different English majors in the industry based on years of teaching experience and rich language knowledge systems. Its purpose is mainly to focus on the content imparted rather than the way it is taught, and the content is relatively traditional and lacks innovative elements. However, most of the college teachers have been limited by the teaching materials in the teaching, focusing on the hard presentation of the content and lacking flexibility and innovation. Besides, because of the different influences of the infrastructure, teaching methods and environment of each university, the traditional teaching mode is more difficult to give students a deeper understanding. And the rigid teaching method is very easy to cause the course to be boring, which will let students lose interest in it in the long run.

\subsection{Pay Too Much Attention to Grammar Training and Ignore Practical Use}

For any discipline, "practice" is undoubtedly the fastest and best way to get information. Simply focusing on theory and light practice will easily lead to certain difficulties in the final practical application, and this method will easily cause a certain imprisonment to the human mind, making it difficult to convert flexibly in the later period. In the process of teaching English, many colleges 
and universities over-emphasize grammar, test and improve students' English proficiency through written tests, while ignore students' practical practice. Grammar is important, but too many grammar rules tend to reduce students' interest in learning English, making it difficult to master English knowledge more comprehensively and systematically. And with respect to the writtenness of language, too strict grammar rules will create obstacles in the process of oral communication and it is difficult to implement flexible conversion of thinking.

\subsection{Teachers' Ability Is Lagging Behind and Team Structure Is Single}

At present, there are not many master's and doctoral programs for English majors in Chinese major universities, and they are narrower in terms of research space and direction. Moreover, in the English teaching of most colleges and universities, the construction of its teachers seems to be lagging behind, the resources of teachers are not enough, and there is no healthy competition. In any subject, teachers play a guiding role in teaching, so their professional level or professionalism has direct or indirect influence on students. However, at present, most colleges lack a strong team of teachers, and there is not enough teacher resources and practical experience to cope with the number of students and teaching needs that are expanded year by year, so that students can not learn enough English knowledge and master the use of English in life. This is extremely unfavorable for students' learning outcomes and the improvement of teaching quality in universities.

\subsection{Single and Boring Teaching Mode}

Most students choose English majors because of their love of English culture rather than English grammar. However, most of the current English teaching modes present a single structural mode that from the silent remember of the word to the parsing of the example sentence to the meticulous note taking. This quickly weakens the enthusiasm that students have when they begin to learn English, making it difficult to persevere in the learning process. In addition to the complex knowledge structure of English, this traditional teaching mode makes students gradually become passive and dependent, mechanically accepting content, and ignoring their own training in comprehensive ability such as listening and speaking. The traditional teaching mode not only reduces the teaching quality in English, but also has a negative impact on the enthusiasm of both teachers and students.

\subsection{Lack of Proper Humanities Education}

Under the current market economy conditions, there are kinds of concepts and cultures existing. Pragmatism and consumerism is popular. These cultural phenomena will inevitably affect schools and students, and negative factors affect the teachers and students a lot. To a certain extent, they even influence the value orientation of teachers and students. Generally speaking, the status quo of English quality education in colleges and universities is not optimistic. Many students have serious utilitarianism at the beginning of their studies. At present, college students generally have deviations in humanities knowledge, cultural vision and discrimination ability is weak, and understanding of some cultures is still in a state of ignorance. Many teachers have the same problem. Some teachers even have doubts about education and personal treatment. They often separate teaching from education, and understand their responsibilities unilaterally and in isolation.

\section{Reform Methods of College English Education under the Background of Quality Education}

English courses have many differences with other courses. In terms of the educational function 
of English courses, we should first take its communicative and practical functions as a prominent point. Under the background of quality education, we should start from the aspects of updating education concepts, innovating teaching content and methods, optimizing teaching objectives, and deepening cultural penetration.

\subsection{Update Concept}

The majority of English teachers are direct implementers of education and teaching. The educational philosophy and ideas of teachers directly affect students' learning and ability. The first thing that should be solved in the implementation of quality education is the ideological aspect. Quality education is first and foremost an educational concept, not just an educational method or an educational mode. The development and implementation of quality education is a systematic project. College English teaching should not only stay in the teaching of subject theory, professional knowledge and skills, but more importantly, it should train students' scientific truth-seeking ideas, methods to deal with problems, and their own personality literacy. Therefore, the majority of teachers must innovate the educational concept, fully recognize the quality education science, enrich connotation and extension, and effectively implement the requirements of quality education in an orderly manner and penetrate into the various steps of English teaching.

\subsection{Strengthen the Culltivation of Students' Moral Education and Humanistic Literacy}

In quality education, we must pay attention to the cultivation of students' moral education and humanistic literacy. This is not only the starting point and the foothold of education, but also an important part of quality education. Previously, our understanding of higher education was slightly biased. On the one hand, we attached great importance to the teaching of students' basic scientific knowledge. On the other hand, we neglected the shaping of students' conducts and other aspects. In recent years, many campus vicious incidents have already sounded the alarm for us. In the process of cultivating students' English knowledge and abilities, teachers must pay attention to the cultivation and edification of their moral education, and unify education and moral education. In terms of educating students on humanistic literacy, we also need to strengthen it. First of all, we should try our best to enrich the content of the textbooks, which try to be close to the students' life and enlighten students' thinking. Teachers should be good at excavating the elements of humanities education in textbooks when preparing lessons, integrating human factors and moral education elements into the explanation of knowledge, and teaching students to distinguish Western culture and improve intercultural communication skills.

\subsection{Embody the Spirit of Innovation in Education and Teaching}

Innovative education refers to an educational mode aiming at cultivating innovative talents, emphasizing the coordination and comprehensive development of students' moral, intellectual, physical and aesthetic aspects. To implement quality education is to attach great importance to students' innovative consciousness and ability, and to cultivate students' independent learning potential and ability. In the process of teaching, teachers should respect individual differences, try to teach students in accordance with their aptitude, promote active participation of students in education and teaching, strengthen students' ability to use language, give full play to students' self-potentials, and unconsciously achieve overall improvement in quality. College students are more active in thinking and are very easy to accept new things and fresh ideas. Therefore, we must try to create a good language learning environment for students, so that students have many opportunities to participate in social practice. Only in this way can they truly appreciate the 
instrumental value of English and the sense of accomplishment of learning, and enhance learning efficiency and interest in learning in a subtle way.

\section{References}

[1] Horwitz, E.k. \& Young, D. J. 1991, Language Anxiety: From Theory and Research to Classroom Implications [M]. Englewood Cliffs, NJ: Prentice Hall.

[2] Krashen, S. D.1985. The Input Hypothesis: Issues and Implications [M]. Longman Inc. New York.

[3] Swain, M.1985. Communicatiove competence: Some roles of comprehensible input and comprehensible out put in its development [A]. In Gass, S and Madden, C. (eds).

[4] Cai Jigang. The Current Stress in College English Teaching [J]. Foreign Language Teaching and Research, 2002, (3).

[5] Huang Guixiang. Analysis of the Training Mode and Employment Status of English Majors in Applied Undergraduate Colleges in Private Universities [J]. Exam Weekly, 2011 (22).

[6] Liu Junhong. Study on the Training Mode of Three-dimensional English Professionals [J]. Journal of Shayang Teachers College, 2008(6). 